Therapeutic Communities: The International Journal of Therapeutic Communities

The school as a therapeutic community

\begin{tabular}{|r|l|}
\hline Journal: & $\begin{array}{l}\text { Therapeutic Communities: The International Journal of Therapeutic } \\
\text { Communities }\end{array}$ \\
\hline Manuscript ID & TC-09-2017-0026.R1 \\
\hline Manuscript Type: & Academic Paper \\
\hline Keywords: & $\begin{array}{l}\text { Teachers, teaching satisfaction, Self Determination theory, therapeutic } \\
\text { community, motivation, wellbeing }\end{array}$ \\
\hline
\end{tabular}




\begin{abstract}
Purpose - The purpose of this study was to explore the facets of Self Determination Theory and the potential relationships with teaching satisfaction in a sample of secondary school teachers $(n=1288)$. The study explored the potential of the school environment in fostering a beneficial community in which personal needs could be met and investigated potential disparities between male and female teachers.

Design/methodology/approach - The study utilised an electronic quantitative questionnaire to collect data from a representative sample. Structural equation modelling was applied and permitted an exploration of potential relationships between the facets of Self Determination Theory and teaching satisfaction, while controlling for specified covariates.
\end{abstract}

Findings - It was shown that the specified model could be effectively applied to both male and female teachers. The results demonstrate that only competence was related to teaching satisfaction in both samples.

Practical implications - Future studies should focus on factors which contribute to teachers' sense of competence within the professional role. Schools need to facilitate this need in order to promote wellbeing within the educational environment.

Originality/value - This is the first known research to explore the specified relationships and the ability of the school environment to foster wellbeing and satisfaction. It is suggested that competence is the more prominent need with regards to teaching satisfaction.

Keywords Teachers, teaching satisfaction, Self Determination theory, therapeutic community, motivation

Paper type Research paper 


\section{The school as a therapeutic environment.}

Teaching can be viewed as a personally rewarding career which may serve to enhance wellbeing through interaction within the school environment (Santoro et al., 2012). The teacher role is multifaceted and challenging, and may be influenced by the beliefs of the teacher, personal motivation and sense of job satisfaction (Klassen et al., 2008). The application of self-determination theory has often been utilised to explain motivation, emotion and behaviour in a variety of work domains (Deci and Ryan, 2000). Esdar et al. (2016) consider motivation as an important factor to individual wellbeing, performance and satisfaction in educational settings. Consequently, the school setting has the potential to act as a therapeutic community in promoting positive psychological benefits for teachers.

According to Self-Determination Theory, environmental conditions which facilitate the psychological needs of autonomy, competence and relatedness are beneficial to ensuring personal development and enabling optimum wellbeing (Deci and Ryan, 2000). Deci and Ryan (2002) consider autonomy to be the perception of being in charge of one's own behaviour and competence is understood as a feeling of personal effectiveness. The psychological sense of being with others encapsulates the concept of relatedness. Consequently, the school setting can provide opportunities to satisfy these needs through mutual participation and engagement (Wagner and French, 2010). In further support, Roth (2007) noted that contextual factors have the ability to facilitate self-determined teaching motivation and contribute to satisfying the needs for autonomy, competence and relatedness. Similarly, research by Wininger and Birkholz (2013) reported that job satisfaction within the teaching role was significantly related to the fulfilment of such innate psychological needs.

Being satisfied with teaching is of paramount importance as it is recognised that teacher wellbeing and student wellbeing is interrelated (Roffey, 2012). Rots et al. (2012) reported that job motivation is dependent on the development of a sense of professional competence within the role. It has been documented that teaching is challenging (Hong, 2012) and Stoll et al. (2006) report that it is necessary for teachers to be proficient within their practice in order to meet the diverse demands of 
the job. Consequently, it may be necessary that teachers continually enhance their professional practice whilst also remaining fully informed of changing legislation which may affect their role (Polk, 2006). Continual reforms within the school sector have often been considered as a contributory factor in teacher overload with the evolving demands impacting teacher wellbeing (Fink, 2003).

Glenville-Cleave and Boniwell (2012) reported that educational reforms may reduce autonomy within the teacher role. This is potentially a cause for concern as Skaalvik and Skaalvik (2014) report that autonomous teaching enhances satisfaction at work. Conversely, Griva and Joekes (2003) suggest that psychological wellbeing is not necessarily related to obtaining job control within the teacher role. Wilkesman and Schmid (2014) also noted that the intrinsic motivation of teachers, whilst facilitated by both competence and relatedness, was only partly facilitated by autonomy. It has been suggested that the overarching and structured attainment culture of contemporary education may offer some explanation of this finding (Brookfield, 2006).

In order to be effective in the professional role, Timms and Brough (2013) suggest that teachers often seek support through meaningful interactions with colleagues, although individual variation is noted. Alhija (2015) noted that female teachers report social support as more necessary in promoting a positive working environment than do their male counterparts. Lui and Ramsey (2008) found that females experience less overall job satisfaction than males. Related research by Guglielmi et al. (2016) found that younger teachers were driven by the opportunity for collegial relationships and personal development. It was further noted that having the opportunity to demonstrate professional competency was more dominant in older teachers.

Owen (2016) further notes that reciprocal collegial relationships may promote a sense of fulfilment. Collaborative teacher working may enhance enthusiasm and confidence which promotes wellbeing and satisfaction; this is made possible within the school setting which fosters a beneficial community to teachers (Huppert and Johnson, 2010; Vescio et al., 2008). The establishment of positive peer relationships contributes to teachers' capabilities by means of a providing a professional learning community (PLC) (Owen, 2016). Stoll et al. (2006) suggest that PLCs foster the enhancement of skills and pedagogical practice which further contribute to teachers' 
sense of competence. From this perspective, the PLC acts as a therapeutic tool in promoting wellbeing for teachers within the school context.

Despite the recognised potential barriers, the school setting has the potential to act as a therapeutic community in promoting positive psychological benefits for its members. Related research has recognised the therapeutic potential of the primary school setting and draws attention to the concept of the school to act as a therapeutic community (Macdonald and Winship, 2016). Such research introduces new avenues for future research to utilise the therapeutic community ideology within educational settings. With this in mind, the context of the school may provide a platform for facilitating teacher wellbeing, positive functioning and the satisfaction of personal needs. To date, research has not explicitly utilised this framework to explore satisfaction in secondary school teachers.

Furthermore, the decline in the teacher workforce at the secondary school level in England (Department for Education, 2017), make this particular teacher population noteworthy of further study. With this in mind, it is necessary to explore factors which may foster a positive school environment in order to promote satisfaction within the teaching role. As it has been shown that the innate needs as advocated by SDT are applicable to the teaching domain, this theoretical framework is consequently suitable for further exploration.

The aim of the current study is to explore the facets of self-determination theory and their relationship with teaching satisfaction. Given that satisfaction within the professional role is necessary for teachers' wellbeing, professional performance and student outcomes, it is necessary to illuminating factors which relate to satisfaction so that future practice can be better tailored for the interests of those within the school community. Furthermore, it is necessary to consider the potential gender diversity that may exist when exploring the impact of psychological needs and teaching satisfaction as previous research has suggested a potential gendered disparity in the teaching experience.

\section{Method}

Participants 
Participants were 1288 (468 males, 820 females) secondary school teachers currently employed in the secondary education sector in England. Participants ranged in age from 21 to 67 years $(M=41.35, S D=10.85)$. Years of teaching practice ranged from 0 to 43 years $(M=13.57, S D=9.86)$. In order to reduce sampling error, the sample was stratified by region and by Local Education Authority (LEA); there are150 Local Education Authorities which are contained within nine larger regions. A 30\% drop out rate was recorded.

\section{Procedure}

Emails were sent to potential participants requesting them to complete the online questionnaire which encompassed demographics, the Basic Psychological Needs at Work scale (Deci \& Ryan, 2000) and the Teaching Satisfaction Scale (Ho \& Au, 2006)

\section{Measures}

Basic Psychological Needs at work Scale (Deci and Ryan, 2000). This is a selfreport measure of psychological needs in the workplace consisting of 21 items which are scored on a 7 -point Likert scale $(1=$ not at all true to $7=$ very true $)$. There are three subscales (autonomy, competence and relatedness). (1) Autonomy (AUT) consists of 7 items, (eg. 'I am free to express my ideas and opinions on the job'). (2) Competence (COM) consists of 6 items, (eg. 'People at work tell me I am good at what I do'). (3) Relatedness (REL) consists of 8 items, (eg. 'I get along with people at work').

Teaching Satisfaction Scale (TSS) (Ho and Au, 2006). This is a self-report measure consisting of 5 items which assess satisfaction within the teaching role. Each item is scored on a 5-point Likert scale ( $1=$ strongly disagree to $5=$ strongly agree). Scores range from 5 to 25, with higher scores reflecting higher levels of teaching satisfaction. Items on this scale include, 'In most ways, being a teacher is close to my ideal' and 'I am satisfied with being a teacher'. 
Analysis

Preliminary analysis was conducted in SPSS 22 to ensure the suitability of data for structural equation modelling (SEM). Descriptive statistics and Pearson productmoment correlation coefficients were analysed for all continuous variables.

The model of teaching satisfaction was specified and assessed in AMOS 22 using structural equation modelling (see figure 1). SEM is a multivariate approach which employs a confirmatory approach to data analysis; permitting testing of a specified model (Kline, 2013). Simultaneous analysis of regression coefficients, means and variances is achieved through the application of SEM. The SEM technique involves a combination of both factor analysis and path analysis.

The first stage is concerned with the measurement level. Using confirmatory factor analysis (CFA) techniques, factor loadings were determined. The fit between the collected data and the specified model was assessed using goodness-of-fit indices: chi square, root-mean-square error of approximation (RMSEA; Steiger, 1990) with 90\% confidence interval (90\% Cl), Tucker Lewis Index (TLI; Tucker and Lewis, 1973) and Comparative Fit Index (CFI; Bentler, 1990). The structural level relates to correlations between the defined variables which are presented pictorially in a path diagram (Cohen and Cohen, 1983).

The SEM technique allows simultaneous testing of the measurement level and structural level and promotes theory testing by verifying associations between observed and latent factors in the specified model (Bryne, 2013). Unlike regression analysis (where only the dependant variable (DV) has an error term), SEM is advantageous in providing explicit estimates of error variance parameters for all latent factors within the specified model (Blunch, 2008). The latent factors of Self Determination Theory (SDT) were autonomy, competence and relatedness (measured by scores obtained from the Basic Psychological Needs at Work scale), and teaching satisfaction (measured by scores on the Teaching Satisfaction Scale). Co-variables included in the model were participants' age and years of teaching practice. The specified model was initially applied to the full sample of teachers to analyse the overall model fit. This incorporates all direct paths from predictors (autonomy, competence and relatedness) and covariates (age and years of teaching 
practice) to teaching satisfaction. This testing was then repeated on a gender split sample in order to test the model on male and female teachers separately.

\section{INSERT FIGURE 1 (SEM) ABOUT HERE}

\section{Results}

The model was first tested on the full sample. This was then repeated on a gender split sample to assess if the model could be fitted to a male only sample and female only sample.

\section{Descriptive statistics and Correlations}

Descriptive statistics including means (M), standard deviations (SD) and ranges for all variables included in the study are presented in Table 1, along with Cronbach's alpha reliability statistics for the utilised measures (Cronbach, 1951). Correlations between the continuous variables included in the study were assessed using Pearson product-moment correlation coefficient.

\section{INSERT TABLE 1 ABOUT HERE}

\section{Structural Equation Modelling (SEM)}

The first step was to analyse the overall fit of the model which incorporates all direct paths from predictors (autonomy, competence and relatedness) and covariates (age and years of teaching practice) to teaching satisfaction.

\section{Full Sample}

In the full sample, the fit of the specified model indicated an acceptable model fit ( $X^{2}$ $(337)=2119.12, p<.05, \mathrm{CFI}=.88, \mathrm{TLI}=.85, \mathrm{RMSEA}=.061[90 \% \mathrm{Cl}=.061 / .067]$.

At the measurement level, all observed variables were significantly correlated with the latent factor they represent (all values were $p<.001$ ). All regression weights ranged from $\beta=.41$ to $\beta=.89$, indicating moderate to strong correlations. These are presented in Table 2. 
The relationships between teaching satisfaction and the latent factors of SDT were investigated while controlling for the specified covariates. These are displayed in Table 3.

A significant direct effect was noted for the relationship between competence and teaching satisfaction $(\beta=.785, p<.001)$. All other predictors and covariates were not significantly associated with the outcome variable.

\section{Male sample}

In the male only sample, the fit of the specified model indicated an acceptable model fit $\left(X^{2}(337)=1113.14, p<.05, \mathrm{CFI}=.85, \mathrm{TLI}=.85\right.$, RMSEA $=.070[90 \% \mathrm{Cl}=.066 / .075]$.

At the measurement level, all observed variables were significantly correlated with the latent factor they represent (all values were $p<.001$ ). All regression weights ranged from $\beta=.38$ to $\beta=.90$, indicating moderate to strong correlations. These are presented in Table 2.

The relationships between teaching satisfaction and the latent factors of SDT were investigated while controlling for the specified covariates. These are displayed in Table 3.

A significant direct effect was noted for the relationship between competence and teaching satisfaction $(\beta=.843, p<.001)$. All other predictors and covariates were not significantly associated with the outcome variable.

\section{Female sample}

In the female only sample, the fit of the specified model indicated an acceptable model fit $\left(X^{2}(337)=1384.12, p<.05, \mathrm{CFI}=.89, \mathrm{TLI}=.87, \mathrm{RMSEA}=.062[90 \% \mathrm{Cl}=\right.$ $.058 / .065]$.

At the measurement level, all observed variables were significantly correlated with the latent factor they represent (all values were $p<.001$ ). All regression weights 
ranged from $\beta=.47$ to $\beta=.89$, indicating moderate to strong correlations. These are presented in Table 2.

The relationships between teaching satisfaction and the latent factors of SDT were investigated while controlling for the specified covariates. These are displayed in Table 3.

A significant direct effect was noted for the relationship between competence and teaching satisfaction $(\beta=.736, p<.001)$. All other predictors and covariates were not significantly associated with the outcome variable.

INSERT TABLES 2 AND 3 ABOUT HERE

\section{Conclusion}

This is the first known research to apply structural equation modelling to investigate the association of Self Determination Theory (Deci and Ryan, 2000) and teaching satisfaction ( $\mathrm{Ho}$ and $\mathrm{Au}, 2006)$. The results demonstrate that only competence is significantly related to teaching satisfaction. Consequently, previous research which has reported that all components of Self Determination Theory relate to satisfaction (fWininger and Birkholz, 2013) is not supported by the current study findings.

With regards to autonomy, one explanation of this finding could be as suggested by Grenville-Cleave and Boniwell, (2012) whereby innovative teaching is restricted due to the structured framework of the schooling environment. Alternatively it may be that autonomy is not necessarily related to wellbeing as teachers may prefer a predefined framework for teaching (Griva and Jockes, 2003). However, the importance of autonomous teaching has been advocated in related research which has focussed on teacher wellbeing (Skaalvik and Skaalvik, 2014). Future studies would be advantageous to further illuminate the importance of autonomy from the teacher viewpoint.

Similarly, the relationship between relatedness and teaching satisfaction was nonsignificant, although previous research has reported the importance of this relationship (Timms and Brough, 2013). It has previously been suggested that positive relationships with colleagues contribute to teachers' sense of competence 
within a professional learning community (Owen, 2016). In this sense, the significance of competence and its association with teaching satisfaction as reported in the current study findings may incorporate elements of such relatedness. It would be beneficial for future research to assess the views of teachers to ascertain the importance of peers in contributing to their professional practice.

What is evident from the current study findings is the therapeutic potential of the school environment to facilitate satisfaction through permitting the need for competence to be achieved. When needs are met this contributes to individual wellbeing (Deci and Ryan, 2002). This standpoint aligns with the therapeutic ideology previously noted within the primary school context (Macdonald and Winship, 2016). The recognised association of competence and teaching satisfaction also demonstrates that the school setting is equally beneficial to both male and female teachers. This is advantageous when considering developing strategies and initiatives in light of the research findings.

The findings of this research support the need for continuing professional development for teachers. This would ensure that teachers remain up to date with the evolving demands of the job and would contribute to competence and impact teaching satisfaction. The results further support previous related research which has highlighted the importance of competency to ensure job satisfaction (Stoll et al., 2006). Furthermore, training which is collaborative would further promote collegial relationships in a PLC framework (Owen, 2016). Development programmes which inspire innovative practice may permit greater teacher autonomy and could further contribute to teaching satisfaction. Such inclusions into a development strategy would further allow schools to act as a therapeutic community by fostering motivation and positive emotions which would not only be of benefit to teachers but may also have positive effects on learners.

A potential limitation of the current study is the application of self-reporting which may not reflect the views of others within the school. Given that the relationship between competence and satisfaction was shown to be significant this is noteworthy of further exploration. An objective measure of competence based on supervisory report or measured performance may consequently contribute to enhancing knowledge on the relationship between competence and satisfaction at work. In 
addition, relatedness as measured in the current study refers to 'people at work' and whilst this is intended to assess collegial relationships it may be that some teachers have interpreted 'people' as students. Future research which explores relatedness with colleagues and students as independent factors may be beneficial as previous research has noted that both are important to wellbeing (Wininger and Birkholz, 2013)

Despite the potential limitations, it is necessary to explore more specifically competence and satisfaction within the teaching role. Research which could illuminate the factors which promote competence from a teacher perspective would be beneficial to guiding relevant training tailored to the needs of teachers. This may serve to explain how a teacher's ability to perform effectively can impact teaching satisfaction, which in turn may positively impact on the wellbeing of teachers. This would be further advantageous as the link between teacher wellbeing and student performance has been previously demonstrated (Roffey, 2012). Thus, the therapeutic potential of the school community is not limited to the micro level, but is beneficial on a more macro scale. Such work is needed if schools are to adopt a therapeutic community ethos to facilitate teacher wellbeing.

\section{References}

Alhija, F. N. A. (2015), "Teacher Stress and Coping: The Role of Personal and Job Characteristics", Procedia - Social and Behavioral Sciences, Vol.185, pp. $374-380$.

Bentler, P. M. (1990), "Comparative fit indices in structural models", Psychological Bulletin, Vol.107, pp. 238-246.

Blunch, N. J. (2008), Introduction to structural equation modelling using SPSS and AMOS, London, Sage Publications.

Brookfield, S. D. (2015), The skilful teacher, on technique, trust, and responsiveness in the classroom ( $2^{\text {nd }}$ ed.). San Francisco, CA: Jossey-Bass.

Byrne B. M. (2013), Structural Equation Modeling with AMOS. Basic concepts, Applications and Programming, $2^{\text {nd }}$ Ed. London, Routledge.

Cohen, J. and Cohen, P. (1983), Applied multiple regression/correlation analysis for the behavioral sciences, $2^{\text {nd }}$ Ed. Hillsdale, $\mathrm{NJ}$, Erlbaum.

Cronbach, L. J. (1951) "Coefficient alpha and the internal structure of tests" Psychometrika, 22, pp.297-334. 
Department for Education. (2017), "School workforce in England: November 2016", available at: https://www.gov.uk/government/uploads (Accessed $2^{\text {nd }}$ August 2017).

Deci, E. L. and Ryan, R. M. (2000), "The 'what' and 'why' of goal pursuits: Human needs and the self-determination of behaviour", Psychological Inquiry, Vol.11, pp. 227-268.

Esdar, W., Gorges, J., and Wild, E. (2016), "The role of basic need satisfaction for junior academics' goal conflicts and teaching motivation”. Journal of Higher Education, Vol.72, pp.175-190.

Fink, D. (2003), "The law of unintended consequences: the 'real' cost of top-down reforms", Journal of Educational Change, Vol. 4 No. 2, pp.105-128.

Grenville-Cleave, B. and Boniwell, I. (2012), "Surviving or thriving? Do teachers have lower perceived control and well-being than other professionals?", Management in Education, Vol.26 No.1, pp. 3-5.

Griva, K., and Joekes, K. (2003), "UK teachers under stress: can we predict wellness on the basis of characteristics of the teaching job?", Psychology and Health, Vol. 18, No. 4, pp.457-471.

Guglielmi, D., Bruni, I., Simbula, S., Fraccaroli, F., and Depolo, M. (2016), "What drives teacher engagement: a study of different age cohorts", European Journal of Psychology of Education, Vol. 31 No. 3, pp.323-340.

Ho, C. L. and Au, W. T. (2006), "Teaching satisfaction scale: measuring job satisfaction of teachers", Educational and Psychological Measurement, Vol. 66, pp. 172-185.

Hong, J. Y. (2012), "Why do some beginning teachers leave the school, and others stay? Understanding teacher resilience through psychological lenses", Teachers and Teaching: Theory and Practice, Vol.18 No.4, pp. 417-440.

Hu, L. and Bentler, P. M. (1999), "Cut off criteria for fit indexes in covariance structure analysis: Conventional criteria versus new alternatives". Structural Equation Modelling, Vol.6, pp. 1-5.

Huppert, F. and Johnson, D. (2010), "A Controlled Trial of Mindfulness Training in Schools: The importance of practice for an Impact on Wellbeing", Positive Psychology, Vol.5, pp. 264-274.

Kline, R. B. (2013), "Assessing statistical aspects of test fairness withstructural equation modelling", Educational Research and Evaluation, Vol.19 No.2, pp. 204-222.

Klassen, R. M. and Chong, W. H. and Huan, V. S. and Wong, I. and Kates, A. and Hannok, W. (2008), "Motivation beliefs of secondary school teachers in Canada and Singapore: A mixed methods study", Teaching and Teacher Education, Vol.24, pp. 1919-1934. 
Liu, X. S. and Ramsey, J. (2008), “Teachers' job satisfaction: Analyses of the Teacher Follow-Up Survey in the United States for 2000 -2001", Teaching and Teacher Education, Vol. 24, pp.1173-1184.

MacDonald, S. and Winship, G. (2016), "The primary school as a therapeutic community" Therapeutic Communities. The International Journal of Therapeutic Communities, Vol. 37 No. 1, pp.18-26.

Owen, S. (2016), "Professional learning communities: building skills, reinvigorating the passion, and nurturing teacher wellbeing and "flourishing" within significantly innovative schooling contexts", Educational Review, Vol.68 No.4, pp. 403-419.

Polk, J. A. (2006), "Traits of Effective Teachers", Arts Education Policy Review, Vol. 107 No. 4, pp.23-29.

Roffey, S. (2012), "Pupil Wellbeing- Teacher Wellbeing: Two sides of the Same Coin?", Educational and Child Psychology, Vol.29 No.4, pp. 9-17.

Roth, G., Assor, A., Kanat-Maymon, Y., and Kaplan, H. (2007), "Autonomous motivation for teaching: How self-determined teaching may lead to self-determined learning", Journal of Educational Psychology, Vol. 99, pp.761-774.

Rots, I., Kelchtermans, G., and Aelterman., A. (2012), "Learning (not) to Become a Teacher: A Qualitative Analysis of the Job Entrance Issue", Teaching and Teacher Education, Vol. 28 No. 1, pp.1-10.

Santoro, N., Pietsch, M., and Borg, T. (2012), "The passion of teaching: learning from an older generation of teachers", Journal of Education for Teaching, Vol. 38 No. 5, pp.585-595.

Skaalvik, E, M. and Skaalvik, S. (2014), "Teacher self-efficacy and perceived autonomy:Relations with teacher engagement, job satisfaction and emotional exhaustion", Psychological Reports: Employment Psychology \& Marketing, Vol 114 No. 1, pp.68-77.

Steiger, J. H. (1990), "Structural model evaluation and modification: An interval estimation approach", Multivariate Behavioural Research, Vol.25, pp. 173-180.

Stoll, L. and Bolam, R. and McMahon, A. and Wallace, M. and Thomas, S. (2006), "Professional Learning Communities: A Review of the Literature.", Journal of Educational Change, Vol.7 No.4, pp. 221-258.

Timms, C. and Brough, P. (2013), "I like being a teacher": Career satisfaction, the work environment and work engagement", Educational Administration, Vol.51 No.6, pp. 768-789.

Tucker, L. R. and Lewis, C. (1973), "The reliability coefficient for maximum likelihood factor analysis", Psychometrika, Vol.38, pp. 1-10.

Vescio, V. and Ross, D. and Adams, A. (2008), "A review of research on the impact of professional learning communities on teaching practice and student learning", Teaching and Teacher Education, Vol.24 No.1 pp. 80-91. 
Wagner, B. D. and French, L. (2010), "Motivation, Work Satisfaction, and Teacher change Among Early Childhood Teachers", Research in Childhood Studies, Vol.24, pp. 152-171.

Wilkesmann, U., and Schmid, C. J. (2014), "Intrinsic and internalized modes of teaching motivation", Evidence - Based HRM, Vol. 2 No. 1, pp.6-27.

Wininger, S, R. and Birkholz, P, M. (2013). "Sources of Instructional Feedback, Job Satisfaction, and Basic Psychological Needs", Innovative Higher Education, Vol.38, pp.159-170. 
[Type text]

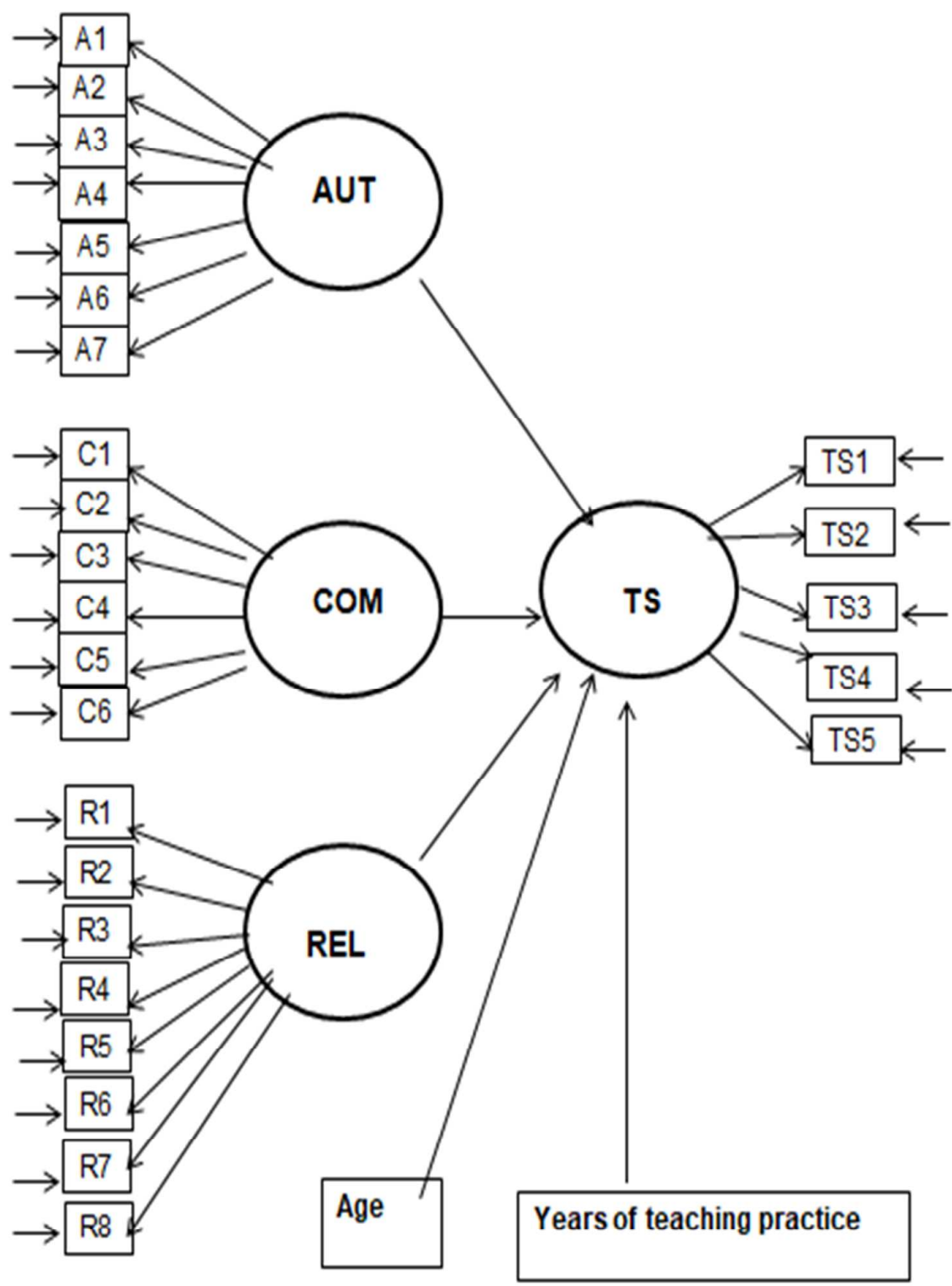

Figure 1. Structural equation model of teaching satisfaction.

AUT= Autonomy; COM= Competence; REL= Relatedness; $\mathrm{TS}=$ Teaching Satisfaction 
Table 1

Descriptive Statistics and Reliability of the Measures included in the study

\begin{tabular}{|c|c|c|c|c|c|}
\hline Scale & M & SD & Range & $\begin{array}{c}\text { Possible } \\
\text { range }\end{array}$ & 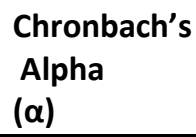 \\
\hline Autonomy & 28.46 & 7.77 & $7-49$ & $7-49$ & .82 \\
\hline Competence & 29.06 & 6.35 & $7-42$ & $6-42$ & .74 \\
\hline Relatedness & 41.07 & 7.98 & $13-56$ & $8-56$ & .84 \\
\hline $\begin{array}{l}\text { Teaching } \\
\text { satisfaction }\end{array}$ & 15.44 & 4.96 & $5-25$ & $5-25$ & .90 \\
\hline
\end{tabular}




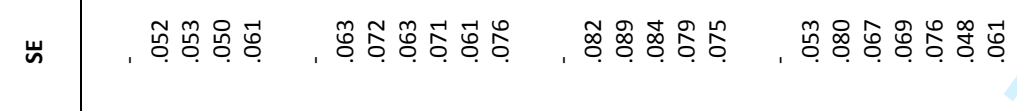

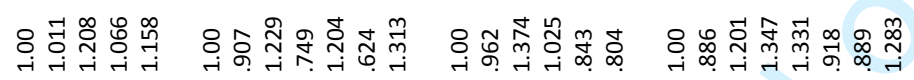

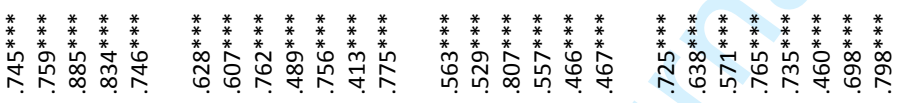

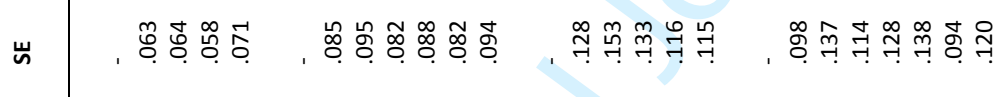

O্ं 命

$\infty$

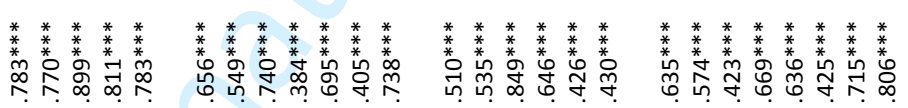




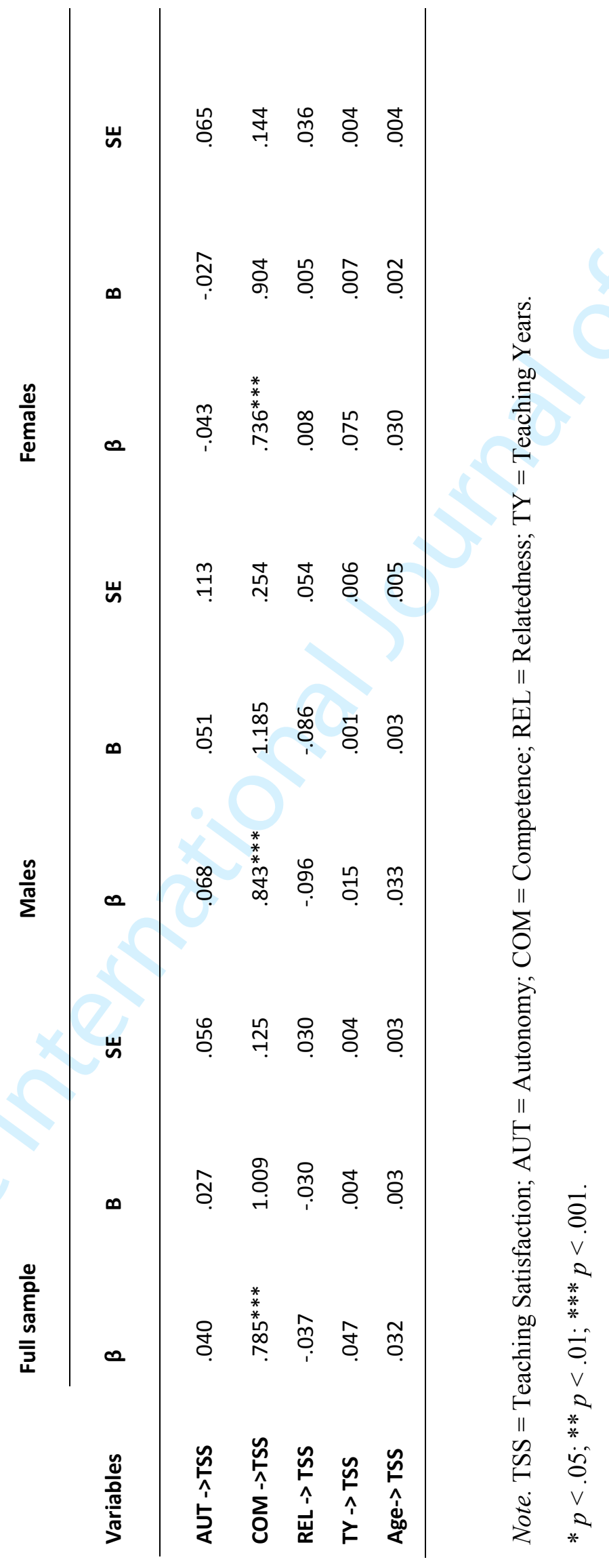

